\title{
Pattern of antimicrobial sensitivity in Enterococcus in case of urinary tract infection, 5 years experiences in a tertiary care hospital
}

\author{
Ashis Kumar Saha ${ }^{1}$ \\ ${ }^{1}$ Professor \& Head of Medicine, MGM Medical College \& LSK Hospital, Kishanganj, Bihar, India \\ *Corresponding Author: Ashis Kumar Saha \\ Email: asissaha2008@gmail.com
}

\begin{abstract}
Introduction: Urinary tract infection is very common in our community mostly in females and enterococcal infection is very frequent. There is gradual development of resistance against this organism thus narrowing the spectrum of susceptibility.

Aims: So, the aim of this study to detect the spectrum of sensitivity pattern in case of enterococcus in case of urinary tract infection.

Materials and Methods: In this retrospective cross sectional study, morning midstream clean-catch urine form total 1550 symptomatic patients was studied for the spectrum of antibiotic susceptibility according to Clinical \& laboratory Standard Institute (CLSI) guideline.

Results: Total 189 patients were infected with enterococci. They showed sensitivity to Vancomycin $(87.83 \%)$, Teicoplanin $(85.18 \%)$, Lenazolid (84.12\%) and nitrofurantoin (74.07\%), and moderate degree of sensitivity in piperacillin-tazobactam (67.19\%), imipenem (64.60\%) and gentamicin (46.56\%) and Amoxycillin-clavulanic acid (54.49\%).

Conclusion: Proper antibiotic-stewardship is ultimate requirement to prevent the development of bacterial resistance. So, regular surveillance as well as monitoring is very much necessary to update the knowledge about the susceptibility pattern of urinary pathogens which will guide the therapy.
\end{abstract}

Keyword: Enterococcus, Symptomatic urinary tract infections, Culture and sensitivity, Tertiary medical centre.

\section{Introduction}

Urinary tract infection (UTI) is one of the most common infection in case community as well as hospital settings worldwide. ${ }^{1-3}$ It is most common in females but in case of elderly its incidence is equal in both men and women. ${ }^{4-6}$ The factors responsible frequency of UTI in females are due to shorter urethra, close proximity to anus and lack of bacteriostatic properties of prostatic secretion. Again, female genital tract is very close to urethra which may lead to spread of infection from one tract to the other. ${ }^{7}$ UTI may be complicated or uncomplicated. Uncomplicated UTI may be asymptomatic bacteriuria, or it may be cystitis, pyelonephritis in case of men and nonpregnant women. Complicated UTI may be due to above causes when there is associated comorbidity, like, diabetes, immunocompromized or any anatomical barrier, pregnancy. Some organisms will be more virulent in glucose environment so history diabetes is very important in case UTI. Symptoms are usually burning sensation during in micturition, frequency or urgency in micturition, hematuria, suprapubic pain or loin pain. Anatomical barrier may be prostate related, foreign body, tumor or stone in urinary tract, obstructed catheter usually hinder the free flow of urine leading to accumulation of urine and it will imbibe the infection. Again after therapy there may be reinfection or relapse of infection. Relapse is due to infection with the same organism by which the patient was infected as it persisted even after treatment. On the other hand reinfection is due the new organism. The organisms responsible for UTI are Escherichia coli, Enterococcus, Klebsiella, Pseudomonas, Streptococci, Staphylococcus Epidemidis, Proteus, Gram Negative Staphylococci, Serratia, Gram Negative Enteric Bacteria and Yeast. ${ }^{6,8,9}$ Now annual incidence of urinary tract infection is nearly 25 million worldwide and $30 \%$ of total UTI is hospital acquired. ${ }^{10}$ Traditionally 7-10 courses of antibiotics are recommended for UTI in males short courses for 3 days even single dose therapy are for females as they mainly suffer from cystitis. Short course of B-lactam is not properly investigated as compared to trimethoprim or nitrofurantoin so it requires extensive studies. ${ }^{11}$ Again in case of hospital acquired acute pyelonephritis, the organisms are resistant to common antibiotics. So, in those cases, broad spectrum antibiotics should be given to start with after sending the urine for culture. Catheter induced UTI is fairly common which may lead to asymptomatic bacteriuria but it can be resolved by removal of catheter. ${ }^{12}$ But now-a-days novel catheters have been introduced because in these catheters bacteria will not be able to adhere which will decrease the incidence of asymptomatic or symptomatic bacteriuria. The catheter may be of silver alloys based or incorporated with rifampicin and minocycline. ${ }^{13,14}$ But from the costing point of view silveralloyed catheter is usually used when it is absolutely necessary to keep the catheter for more than months. ${ }^{15}$ In case of pregnancy, nearly 5\% suffer from asymptomatic bacteriuria and again few of these patients enter into pyelonephritis and these are usually responsible for lowbirth weight babies, pre mature delivery, preeclampsia or hypertension. So, repeated urinary culture to detect asymptomatic bacteriuria should be done and follow-up antibiotic treatment should be done to reduce the incidence of UTI and complications during pregnancy. ${ }^{16,17}$ Following measures can be taken to reduce the incidence of UTI, like, antiseptic use after intercourse, cranberry or blueberries juice containing tannis as it decrease the incidence of pathogens to the uroepithellium, regular cleaning of the urethral opening, intravaginal application of topical estrogen and long courses of low-dose antibiotics. But now-a-days 
indiscriminate and improper use of antibiotics, inadequate dose, inadequate duration, frequent change of antibiotic usually lead to resistance of many organisms to many broad spectrum antibiotics and there is change in the pattern of sensitivity of many organisms to different antibiotics. This sensitivity pattern again varies in different geographical areas depending upon the use of antibiotics. Therefore, the aim of this study was to know the pattern of sensitivity of enterococcus against different antibiotics in this geographical area so that it can be used as guideline for proper treatment of all types of patients.

\section{Materials and Methods}

The study was started after getting permission from the local ethical committee of our hospital. This is a cross sectional retrospective study of five years from our medical college. Total 1550 patients with suggestive symptoms of UTI were taken in this study. Morning midstream clean catch urine specimen were collected for microbial analysis. No mixed infections were encountered. Urine specimen was inoculated by pre calibrated platinum loop in MacConkey agar and 5\% sheep blood agar media to deliver a measured quantity (1.0 $\mu \mathrm{l})$ to detect the growth of the susceptable bacteria. Enterococcus was detected on brain-heart infusion agar (Becton Dickinson Microbiology systems, Cockeysville, MD, USA) supplemented with $2000 \mathrm{mg} / \mathrm{L}$ streptomycin as well as $500 \mathrm{mg} / \mathrm{L}$ gentamicin. At $37^{\circ} \mathrm{C}$ for 48 hours colony forming unit (CFU) count of $10^{5} / \mathrm{ml}$ was considered as positive. Then, antibiotic susceptibility was tested by using Kirby-Bauer disk diffusion method following CLSI guideline. For this commercial antibiotics were used for sensitivity test. Following antibiotic disc were taken from the manufacturers, Becton Dickinson and Company, USA, Oxoid Ltd. UK: Imipenem $(10 \mu \mathrm{g})$, amikacin $(30 \mu \mathrm{g})$, nitrofurantoin $(300 \mu \mathrm{g})$, gentamicin $(30 \mu \mathrm{g})$, tobramycin $(30$ $\mu \mathrm{g})$, ceftazidime $(30 \mu \mathrm{g})$, ceftriaxone $(30 \mu \mathrm{g})$, ciprofloxacin $(5 \mu \mathrm{g})$, amoxicillin-clavulanic acid $(20 / 10 \mu \mathrm{g})$, ampicillin $(25 \mu \mathrm{g})$, Vancomycin $(30 \mu \mathrm{g})$, linezolid $(30 \mu \mathrm{g})$, piperacillin-tazobactam $(100 / 10 \mu \mathrm{g})$, Teicoplanin $(30 \mu \mathrm{g})$, azithromycin $(15 \mu \mathrm{g})$, cephalexin $(30 \mu \mathrm{g})$ were used. Staphylococcus aureus (ATCC 25923), Pseudomonas aeruginosa (ATCC 27853) and E. coli (ATCC 25922) were used as control strains.

\section{Statistical method}

Obtained data were entered in the STATISTICAL PACKAGE SOCIAL SCIENCES version 17 for proper evaluation for calculation of percentage for different susceptibility pattern.

\section{Result}

Total number of patients included was 1550 and total number of affected patients with enterococcus was 189 $(12.19 \%)$.
Table 1: Pattern of antimicrobial Sensitivity pattern of Enterococcus fecalis infection of urinary tract $(\mathrm{n}=189)$

\begin{tabular}{|l|c|c|}
\hline Antibiotic & Sensitivity & Percentage \\
\hline Amoxycillin & 53 & 28.04 \\
\hline $\begin{array}{l}\text { Amoxycillin-Clavulanic } \\
\text { acid }\end{array}$ & 103 & $\mathbf{5 4 . 4 9}$ \\
\hline Piperacillin-Tazobactam & 127 & $\mathbf{6 7 . 1 9}$ \\
\hline Cefoparazone-Tazobactam & 2 & 1.05 \\
\hline Cefuroxime & 1 & 0.53 \\
\hline Cefotaxime & 1 & 0.53 \\
\hline Cefoxitin & 1 & 0.53 \\
\hline Ceftazidime & 1 & 0.53 \\
\hline Ceftriaxone & 1 & 0.53 \\
\hline Cefepime & 0 & 0 \\
\hline Azithromycin & 0 & 0 \\
\hline Aztreonam & 2 & 1.05 \\
\hline Ertapenem & 3 & 1.58 \\
\hline Imipenem & 124 & $\mathbf{6 5 . 6 0}$ \\
\hline Meropenem & 13 & 6.87 \\
\hline Gentamicin & 88 & $\mathbf{4 6 . 5 6}$ \\
\hline Tobramycin & 10 & 5.29 \\
\hline Netilmicin & 26 & 13.75 \\
\hline Amikacin & 16 & 8.46 \\
\hline Norfloxacin & 42 & 22.22 \\
\hline Ciprofloxacin & 60 & 31.74 \\
\hline Ofloxacin & 53 & 28.04 \\
\hline Levofloxacin & 66 & 34.92 \\
\hline Cotrimoxazole & 6 & 3.17 \\
\hline Chloramphenicol & 5 & 2.64 \\
\hline Tetracycline & 6 & 3.17 \\
\hline Tigicycline & 4 & 2.11 \\
\hline Vancomycin & 166 & $\mathbf{8 7 . 8 3}$ \\
\hline Teicoplanin & 159 & $\mathbf{8 5 . 1 8}$ \\
\hline Lenazolid & 11 & $\mathbf{8 4 . 1 2}$ \\
\hline Polymyxin B & 4 & 5.82 \\
\hline Colistin & 140 & $\mathbf{7 4 . 0 7}$ \\
\hline Ticarcillin & & \\
\hline Nitrofurantoin & & \\
\hline & & \\
\hline
\end{tabular}

Table 1 showed highest dgree of sensitivity in case of Vancomycin $(87.83 \%)$, Teicoplanin $(85.18 \%)$, Lenazolid $(84.12 \%)$ and nitrofurantoin $(74.07 \%)$, and moderate degree in piperacillin-tazobactam (67.19\%), imipenem (64.60\%) and gentamicin $(46.56 \%)$ and Amoxycillin-clavulanic acid $(54.49 \%)$. Table 1 also demonstrated $100 \%$ resistance to cefepime and azithromycin, less than $5 \%$ sensitivity to other fourth generation of cephalosporin, aztreonam, ertapenem, ticarcillin, Cotrimoxazole, chloramphenicol, tetracycline, Tigicycline. Fluoroquinolones demonstrated mild degree of sensitivity (lowest was the Norfloxacin $22.22 \%$ and highest was levofloxacin $34.92 \%$ ).

\section{Discussion}

Since bacterial infection of the urinary tract is most common in our community hence it needs urgent attention. ${ }^{18}$ So identification of the organism is of prime importance as it detects the susceptibility of the organism to the specific 
antibiotic which can cure the patient. Empirical use and improper duration of the antibiotic administration will lead to resistance to that antibiotics which may be responsible for the emergence of multidrug resistant organism in the community as well as in the hospital settings. This resistance may be due to development of spontaneous mutation, development in the enteric bacteria by $\mathrm{R}$ plasmids which is responsible multidrug resistance. Similarly, another study demonstrated $100 \%$ sensitivity to vancomycin, lenazolid. ${ }^{19}$ Sharifi et al. demonstrated $18.6 \%$ resistance against enterococcus as compared to this present study. ${ }^{20}$ One study from South India demonstrated $81 \%$ sensitivity for vancomycin to enterococcus. ${ }^{21}$ Antibiotic resistance cannot explain the virulence of enterococci. Because any infection in the body follows a common sequence of events, like, colonization followed by adhesion to host tissues, invasion of the host tissues and resistance to the host defense mechanism. Now the pathogen directly infects the urinary tract by toxin production or indirectly by producing inflammation produces for pathological changes. ${ }^{22}$

In the antibiogram of Khan IU et al, in the year 2014 enterococcus was susceptible to Lenazolid, vancomycin and Teicoplanin are $100 \%$ sensitive and nitrofurantoin was 92.3\% sensitive which was very similar to this present study where this organism are highly susceptable to these drugs (vancomycin $87.83 \%$, Teicoplanin $85.18 \%$, Lenazolid $84.12 \%$ and nitrofurantoin $74.07 \%$ ). ${ }^{23}$ On the other hand, the present study demonstrated $65.60 \%$ sensitivity to imipenem whereas the study of Khan IU et al. it was nearly $92 \%$.

This study showed that only $12.19 \%$ patient was affected by enterococcus related urinary tract infection. It is nearly same in the study done by Setu SK et al.in 2016 (268 out of total number affected 2287, 11.67\%). ${ }^{24}$

Significant resistance was observed in case of most commonly used antibiotics, like, fluoroquinolones for their broad-spectrum action, bacterial potency, well tolerance to the patients, good oral bioavailability and excellent post antibiotic effect. But due to progressively development of resistance enterococcus in this present study demonstrated low sensitivity $(31.74 \%--34.92 \%)$ as shown in the study done by Setu et al. ${ }^{24}$

\section{Conclusion}

Due to empiric use of antibiotics in inadequate dose for improper duration without proper culture and sensitivity lead to development of multidrug resistant bacteria. Thus, there is gradual narrowing of the spectrum of antibiotic sensitivity for any bacteria which ultimately increases the mortality of the patient. So, proper antibiotic-stewardship is the ultimate requirement to prevent the development of bacterial resistance. So, regular surveillance as well as monitoring is very much necessary to update the knowledge about the susceptibility pattern of urinary pathogens which will guide the therapy.

\section{Acknowledgement}

We are very thankful for the laboratory technician for providing us the information of this records.

\section{Source of funding}

Nil.

\section{References}

1. Akortha EE, Ibadin OK. Incidence and antibiotic susceptibility pattern of staphylococcus aureus, amongst the patients with burinary tract infection in UBTH Benin city, Nigeria. Afr J Biotechnol 2008;7:1637-40.

2. Dalela G, Gupta S, Jain DK, Mehta P. Antibiotic resistance pattern in uropathogens at a tertiary care hospital at Jhalawar with special reference to ESBL Amp-C $\beta$-Lactamase and MRSA production. J Clin Diagn Res 2012;6:645-51.

3. Bhattacharya S. ESBL-From petri dish to the patient. Indian $J$ Med Microbiol 2006;24:20-4.

4. Rock W, Colodner R, Chazan B, Elias M, Raz R. Ten years surveillance of antimicrobial susceptibility of community acquired Escherichia coli and other uropathogens in Northern Israel. Med Assoc J 2007;9:803-5.

5. Jawetz E, Melnick. Clinical correlations: urinary tract, 1995; Medical Microbiology, $20^{\text {th }}$ Ed. London, UK, Prentice Hall Intl Inc. 634.

6. Calvin MK. Urinary tract infections in females. Clin Infec Dis 1994;18:1-12.

7. Epstein JI. The lower urinary tract and male genital tract system, chapter 21 in "Robbins and Cotran Pathologic basis of disease". $8^{\text {th }}$ ed. By Kumar V, Abbas AK, Fausto N, Aster JC, Elsevier, Haryana, India.

8. Atlas RM. Principles of microbiology, Missouri, St. Louis, USA: CV Mosby Company, 1995; 491.

9. Mark ER, Gordon LA. Coagulase negative staphylococci: pathogens associated with medical progress. Clin Infec Dis 1994;19:231-45.

10. Abu Shaqra. Occurrence and antibiotic sensitivity of Enterobacteriaceae isolated from a group of Jordanian patients with community acquired urinary tract infections. Cytobios 2000;101:15-21.

11. Warren JW, Abrutyn E, Herbal JR. Guidelines for antimicrobial treatment of uncomplicated acute bacterial cystitis and acute pyelonephritis in women. Clin Infect Dis 1999;29:745-58.

12. Godfrey KM, Lindsay EN, Ronald AR. How long catheteracquired urinary tract infection in women should be treated? Ann Inter Med 1991;114:713-9.

13. Newton T, Still JM, Law E. A comparison of the effect of early insertion of standard latex and sinver-impregnated latex Foley catheters on urinary tract infections in burn patients. Infect Control Hosp Epidemiol 2002;23:217-8.

14. Darouchie RO, Smith JA, Hanna H. Efficacy of antimicrobial impregnated bladder catheters in reducing catheter associated bacteriuria: a prospective randomized, multicenter clinical trial. Urol 1999;54:976-81.

15. Plowman R, Graves N, Esquivel J. An economic model to assess the cost and benefits of the routine use of silver alloy coated urinary catheters to reduce the risk of urinary tract infections in catheterized patients. J Hosp Infect 2001;48:3342.

16. Mayon-White RT, Ducel G. An international survey of the prevalence of hospital acquired infections. J Hosp Infect 1988;11(suppl):43-8.

17. Fisher JF, Newman CL, Shobel JD. Yeast in the urine: Solutions for a budding problem. Clin Infect Dis 1995;20:1839. 
18. Kabira AN, Ochola P, Khamadi SA. Isolation and antimicrobial susceptibility testing of Escherichia coli causing urinary tract infection. J App Bioaci 2009;22:1320-5.

19. Urinary tract infection in diabetics - A five year retrospective study on the prevalence of bacterial isolates and its antibiotic susceptibility patterns in a tertiary care hospital in South India. Jagadeeswaran G, Ansari MZ, Rajangam T. Int J Contemp Med Res 2018;5(4):1033-7.

20. Sharifi Y, Hassani A, Ghotaslou R. Virulence and antimicrobial resistance in enterococci isolated from urinary tract infection. Adv Pharmacol Bull 2013;3(1):197-201.

21. Abdulla MC, Feroz P, Jenner Jamshad Ajungal. Int J Res Med Sci 2015; 3:2576-9.

22. Johnson AP. The pathogenicity of enterococci. J Antimicrob Chemother 1994; 33(6):1083-9.

23. Khan IU, Mirza IA, Ikram A, Afzal A. Antimicrobial susceptibility pattern of bacteria isolated from patients with urinary tract infection. J Coll Physicians Surg Pak 2014; 24(11):840-4.

24. Setu SK, Sattar AN, Saleh AA, Roy CK, Ahmed M. Study of bacterial pathogens in urinary tract infection and their antibiotic resistance profile in a tertiary care hospital of Bangladesh. Bangladesh J Med Microbiol 2016;10(01):22-6. 